\title{
Affective Learning in Physical Education: A Systematic Review
}

\author{
Eishin Teraoka \\ The University of Strathclyde and Keio University
}

\author{
Heidi Jancer Ferreira \\ Federal Institute of Education, Science and \\ Technology of South of Minas Gerais-IFSULDEMINAS and \\ São Paulo State University
}

\author{
David Kirk \\ The University of Strathclyde and \\ The University of Queensland
}

\author{
Farid Bardid \\ The University of Strathclyde and Ghent University
}

\begin{abstract}
Purpose: The purpose of this study was to carry out a systematic review of intervention programs that have addressed affective learning outcomes within physical education and to explore pedagogical practices in alignment with teaching, lesson content, and learning outcomes. Method: The literature search was conducted in accordance with the Preferred Reporting Items for Systematic Reviews and Meta-Analyses statement. Included were 26 peer-reviewed pedagogical studies of physical education programs that addressed affective outcomes and reported fidelity of implementation. Results and Discussion: Affective outcomes were grouped into four themes: motivation, emotional responses, self-concept, and resilience. The findings showed that offering choice, encouraging peer feedback, asking deductive questions, focusing on personal improvement, and differentiating are effective teaching strategies that were widely used to support affective learning in children and adolescents. This review highlights the importance of fidelity of implementation to understand how intervention programs are delivered.
\end{abstract}

Keywords: fidelity of implementation, intervention programs, motivation, pedagogy, social and emotional learning

Affective learning has long been viewed as a legitimate aspiration for physical education programs, but typically as a hoped-for by-product rather than a directly and intentionally pursued outcome. However, recent interventions in physical education have considered various aspects of affective learning as direct outcomes of school programs. These pedagogical interventions that view learning in the affective domain as directly intended outcomes of physical education can be defined as "pedagogies of affect" (Kirk, 2020, p. 151). As noted by Hellison (1995), affective learning occurs more often when it is planned for and when teaching directly reflects the desired learning outcomes. In this sense, it is important to consider the aspects of pedagogy that influence students' affective learning outcomes.

Researchers in physical education have claimed health benefits as a major outcome of their subject over many years (Cale \& Harris, 2013; Corbin, 2012). Recently, mental health issues among young people (e.g., poor body image, bullying victimization, depression, and low self-esteem) have been highlighted as major concerns (Inchley et al., 2016; Patel, Flisher, Hetrick, \& McGorry, 2007), which has led to increased attention to the affective domain and

\footnotetext{
Teraoka, Kirk, and Bardid are with the School of Education, The University of Strathclyde, Glasgow, United Kingdom. Teraoka is now with the Institute of Physical Education, Keio University, Yokohama, Japan. Ferreira is with the Federal Institute of Education, Science and Technology of South of Minas Gerais-IFSULDEMINAS, Poços de Caldas, Brazil; and with Institute of Biosciences, São Paulo State University, Rio Claro, Brazil. Kirk is also with the School of Human Movement Studies, The University of Queensland, Brisbane, Queensland, Australia. Bardid is also with the Department of Movement and Sports Sciences, Ghent University, Ghent, Belgium. Teraoka (eishin.teraoka@keio.jp) is corresponding author.
}

its relationship to health and well-being. Pedagogical research in the affective domain is important because evidence for the enhancement of affective outcomes within physical education might produce positive benefits to young people's mental health. The affective domain includes a range of outcomes such as motivation, enjoyment, and self-esteem (Bailey et al., 2009), which are significantly associated with positive mental health and psychological well-being (Kirk, 2020). For instance, Van den Berghe, Vansteenkiste, Cardon, Kirk, and Haerens (2014) showed that autonomous motivation supports psychological well-being. Furthermore, Moksnes and Reidunsdatter (2019) found that higher self-esteem predicted higher levels of mental well-being and lower levels of depression and anxiety in adolescents. There is a growing awareness of the significance of affective learning outcomes as a central pedagogical concern among physical education teachers, but also an acknowledgement that teachers may have limited skills and resources to facilitate affective learning (Kirk, 2020).

A number of physical education programs have shown positive results for the achievement of affective learning outcomes. In their literature review, Hastie, de Ojeda, and Luquin (2011) found that programs based on Sport education (Siedentop, 1994) can help develop students' cooperation, empathy, self-discipline, enthusiasm, enjoyment, fair play behavior, and motivation (see also Chu \& Zhang, 2018). Similarly, Harvey and Jarrett (2014) found changes in students' affective outcomes including fun, motivation, and positive attitudes toward peers through game-centered approaches such as Teaching Games for Understanding (TGfU; Bunker \& Thorpe, 1982) and Tactical Games Model (Mitchell, Oslin, \& Griffin, 2006). In a systematic review on Teaching Personal and Social Responsibility (TPSR; Hellison \& Wright, 2003), Pozo, 
Grao-Cruces, and Pérez-Ordás (2018) reported an improvement in students' self-confidence, self-esteem, self-efficacy, and selfcontrol. Furthermore, Oliver, Hamzeh, and McCaughtry (2009) found that girls were more willing to engage in and enjoy physical education through the use of an "activist approach." A review of motivational climate interventions adopting the TARGET framework (i.e., task, authority, recognition, grouping, evaluation and time; Epstein, 1989) showed that there were positive effects on affective outcomes such as attitude and enjoyment (Harwood, Keegan, Smith, \& Raine, 2015). These studies showed that pedagogical models and programs can positively influence affective learning in physical education. Nonetheless, these reviews focused on one specific model or approach. The present review examines a range of pedagogical interventions (i.e., models and programs) and their effect on affective outcomes. An additional benefit of the current review will be to specifically articulate common pedagogical practices across interventions that produce positive changes in affective learning.

There are also a number of reviews that have explored the effectiveness of school-based interventions on psychological variables such as motivation and enjoyment (Burns, Fu, \& Podlog, 2017; Demetriou \& Höner, 2012). However, while these studies have provided information on learning outcomes and how these were assessed, they provided little information on other aspects of pedagogy (i.e., teaching strategies and lesson content). To understand how and why affective learning occurs through intervention programs, it is important to provide information on all aspects of pedagogy (i.e., curriculum, learning, teaching, and assessment). This review will focus on how the alignment of teaching and lesson content can influence affective learning. Another important factor, which is rarely reported in literature reviews, is fidelity of implementation. Fidelity of implementation refers to the degree to which an intervention is delivered as it is originally intended (Escartí, Llopis-Goig, \& Wright, 2018). To further understand physical education programs and their adoption in practice, it is crucial to consider information on intervention implementation including a description of core elements (e.g., a table that provides examples of where these are present in lessons) and monitoring of program compliance (e.g., lesson observations with a checklist; Hastie \& Casey, 2014). Taking fidelity of implementation into account is of pedagogical importance because it not only reveals the feasibility of implementing an intervention program (Dusenbury, Brannigan, Falco, \& Hansen, 2003), but it also enables us to discuss alignment among teaching, lesson content, and learning outcomes. Therefore, the purpose of the current study is to conduct a systematic review of research studies on affective learning in physical education programs that have demonstrated intervention fidelity.

\section{Method}

\section{Search Strategy}

In the initial phase of the literature search, we conducted manual searches in issues of six pedagogical journals published from January 2012 until December 2018. The purpose of this process was to identify currently used terms and concepts in the affective domain and use them as key search words for the next phase. Six prominent pedagogical journals in the field of physical education were selected: (a) European Physical Education Review; (b) Journal of Teaching in Physical Education; (c) Research Quarterly for Exercise and Sport; (d) Sport, Education and Society; (e) Physical Education and Sport Pedagogy; and (f) Asia-Pacific Journal of Health, Sport and Physical Education (now called Curriculum Studies in Health and Physical
Education). Papers in this manual search were included if the study investigated affective learning, which covers psychological and emotional aspects that include feelings, beliefs, aspirations, and attitudes (Bailey et al., 2009). Results revealed that the following concepts are currently being used regarding the affective domain in physical education: motivation, perceived competence (including perceived physical competence and physical self-concept), attitude, interest, enjoyment, pleasure, and body image.

In the next phase, a literature search was conducted in accordance with the Preferred Reporting Items for Systematic Reviews and MetaAnalyses (PRISMA) statement (Moher, Liberati, Tetzlaff, \& Altman, 2009). The PRISMA is a useful and comprehensive approach for searching and identifying relevant studies in the literature in a systematic manner (Moher et al., 2009). The PRISMA Flow Diagram was adopted to describe the process for selecting studies including information resources, eligibility criteria, and screening (see Figure 1). The PRISMA 2009 checklist was followed to report eligibility criteria, risk of bias in the included studies, study selection, data extraction, study characteristics, and synthesis of results. Previous reviews within the field of physical education were consulted as well (Chu \& Zhang, 2018; Pozo et al., 2018). However, not all of the checklist items were adopted. For instance, as this review synthesized evidence from both quantitative and qualitative studies and the data were too heterogeneous, no meta-analysis was conducted.

A search, from January 1, 2007 to December 31, 2018, was carried out in four electronic databases: ERIC, Physical Education Index (now called Sports Medicine \& Education Index), PsycINFO, and SPORTDiscus. The databases were chosen as they include articles published in journals on physical education and affective learning. The starting date of the search was 2007 because the present review aimed to include all relevant studies published as the prior review of Bailey et al. (2009) on the educational benefits of physical education, which covered the literature up to 2006. To capture relevant research on the affective domain in physical education, a combination of the following key words was used (including the concepts that were identified in the manual search) in the electronic searches: ("affective development" OR "affective benefit" OR "mental health" OR "psychological development" OR "psychological benefits" OR "psychological wellbeing" OR "psychological well-being" OR "psychological benefit" OR "emotional development" OR "emotional wellbeing" OR "emotional wellbeing" OR "emotional benefit" OR "motivation" OR "perceived competence" OR "perceived physical competence" OR "physical self-concept" OR "attitude" OR "interest" OR "enjoyment" OR "pleasure" OR "body image" OR "social and emotional learning" OR "personal and social responsibility") AND ("adoles*" OR "teen*" OR "child*” OR "student" OR "youth" OR "boy" OR "girl” OR "primary" OR “elementary" OR "secondary" OR "high" OR "grade”) AND ("Physical Education" OR "PE" OR "school sport*”).

\section{Eligibility Criteria}

The criteria for inclusion in this systematic review were studies: (a) available in English; (b) peer reviewed; (c) with quantitative or qualitative measures of students' affective learning outcomes; (d) conducted in a physical education setting; (e) involving children and adolescents (aged 3-18 years); (f) addressing students' affective outcomes as primary learning outcomes; $(\mathrm{g})$ delivering an intervention program; (h) reporting information on affective outcomes (e.g., motivation), teaching (e.g., teaching strategy), and lesson content (e.g., overview of implemented program content); and (i) reported procedures to ensure the fidelity of implementation 


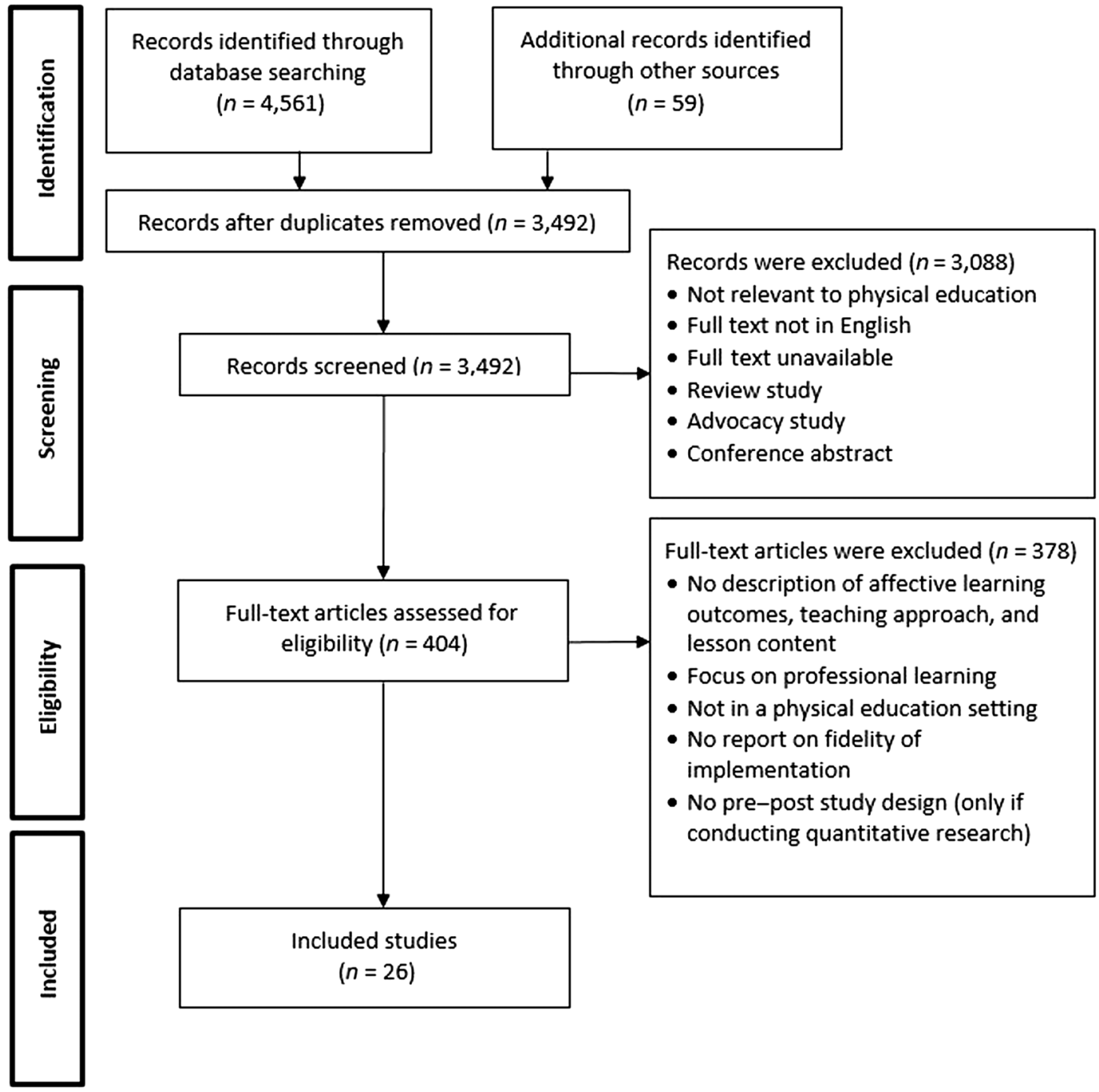

Figure 1 - Preferred Reporting Items for Systematic Reviews and Meta-Analyses flow diagram illustrating the literature search.

during the teaching practice (e.g., lessons were videotaped and analyzed by researchers or experts, and a sample of lessons was observed by researchers or experts). Quantitative studies with a pre-post study design were included in the review; qualitative studies did not require a pre-post study design, but did need to include discussion of students' changes or improvements in affective learning. Mixed-methods studies had to meet the aforementioned criteria as relevant for each method.

Studies were excluded if they were (a) not available in full text, (b) review articles, (c) advocacy or protocol studies, (d) conference abstracts, (e) focused on teachers' professional learning rather than students' learning (e.g., intervention focused on helping teachers adopt autonomy-supportive teaching), and (f) lacking information on fidelity of implementation. Studies were excluded if they did not describe how they evaluated fidelity of implementation, even though the teachers were trained before the implementation.

\section{Screening and Accessing for Eligibility}

There were two stages for screening and assessing for eligibility to minimize the risk of bias in selecting studies. First, two of the authors assessed independently each identified study for relevance to the affective domain based on the title and abstract. Studies were excluded if the two authors agreed they were not relevant. Second, the two authors evaluated the full text of relevant studies for inclusion and assessed whether each study contained the three elements of pedagogy (i.e., learning outcomes, teaching, and lesson content). Any differences in evaluation were resolved through discussion between the two authors. Consensus was obtained for all included studies.

\section{Quality Assessment}

A checklist was used to assess the quality of included studies, based on the Strengthening the Reporting of Observation Studies in Epidemiology statement (Vandenbroucke et al., 2007) and the Consolidated Standards of Reporting Trials statement (Moher, Schulz, \& Altman, 2001). This quality assessment was necessary to exclude any low-quality studies. The following features were selected with reference to recent systematic reviews of pedagogical research (Chu \& Zhang, 2018; Pozo et al., 2018): (a) were the background and rationale for the study explained, (b) did the description of the study design include all information on location and participants, (c) were the period of program duration and the number of lessons described, (d) did the study include a control group, (e) was the method of data analysis described, (f) did the study report internal validity (effect sizes for quantitative studies; 
triangulation methods for qualitative studies), and (g) did the study discuss key results with reference to the study objectives? Each criterion was rated with 1 (yes) or 0 (no) and subsequently summed to provide a quality score. This assessment was undertaken by two authors. The two authors assessed the studies independently. A consensus meeting took place to resolve conflicts in rating. Studies were considered to be of high quality if their quality score was at least 6 . Lower scores indicated medium quality (4-5) or low quality $(<3)$. The results showed that 20 studies were identified as high quality, and six studies were identified as medium quality. There were no low quality studies to be excluded.

\section{Data Extraction}

Relevant information from the included studies was extracted following the guidelines by Harris, Quatman, Manring, Siston, and Flanigan (2014). Review categories were defined as follows: author(s), year, geographic location, sample size, age range, school settings, program content and teaching, program duration, fidelity of implementation measure, methodology, and results. The categories were chosen according to recent systematic reviews of pedagogical research (Chu \& Zhang, 2018; Pozo et al., 2018). Also, deductive thematic analysis based on theories and measures used in the studies was used to identify themes of affective learning.

\section{Results}

\section{Study Selection}

The process of study selection through the PRISMA Flow Diagram is detailed in Figure 1. A total of 4,620 studies was identified through database searching and manual searching. After 1,128 duplicates were removed, 3,492 studies were screened based on title and abstract. Following the screening process, 404 full text articles were assessed with the eligibility criteria. As a result of this assessment, a total of 26 studies were included in this systematic review.

\section{Intervention Characteristics}

Geographic location. The studies were conducted in the United States $(n=9)$, Spain $(n=7)$, Greece $(n=3)$, Switzerland $(n=3)$, Canada $(n=1)$, Italy $(n=1)$, Scotland $(n=1)$, and Turkey $(n=1)$. In terms of cultural commonality, most studies conducted in the United States referred to the importance of affective outcomes (e.g., motivation) in obesity prevention and conceptualized affective learning as foundational for increasing physical activity in and outside school. In most of the other countries (i.e., Spain, Greece, Canada, Italy, Scotland, and Turkey), increasing physical activity in physical education and outside school was also the justification for focusing on affective learning. There were some exceptions in the United States, Spain, and Switzerland. For instance, studies adopting TPSR emphasized self-efficacy and life skills as primary intended outcomes for affective learning (Escartí, Gutiérrez, Pascual, \& Llopis, 2010; Wright \& Burton, 2008). In other studies, affective learning was used to address mental health issues such as stress and negative emotions (Lang et al., 2016, 2017; Schmidt, Valkanover, Roebers, \& Conzelmann, 2013).

School setting and program duration. The number of studies in primary (or elementary) and secondary (or middle/high) school was four and 20, respectively. Two studies were conducted in both primary and secondary schools. Most intervention studies took place in a coeducational setting, except for two, which took place in a single-sex class (i.e., girls only; Bortoli, Bertollo, Vitali, Filho, \& Robazza, 2015; Neumark-Sztainer et al., 2010).

The duration of the studies ranged from 4 weeks to 3 years (see Table 1). Nineteen studies involved programs less than 3 months in duration. Five studies included programs between 3 months and 7 months. Only two of the studies had a duration of more than 1 year.

Program content and teaching. The 26 studies included different intervention programs and addressed one or more affective outcomes. Fourteen studies used pedagogical models, including Sport education (Cuevas et al., 2016; Perlman, 2010, 2011; Perlman \& Caputi, 2017; Perlman \& Goc Karp, 2010; Wallhead et al., 2010, 2014), TPSR (Escartí et al., 2010; Wright \& Burton, 2008), Cooperative Learning (Fernandez-Rio et al., 2017), Tactical Games Model (Harvey et al., 2017), TGfU-based autonomy supportive teaching (Mandigo et al., 2008), a hybrid of Sport education and TPSR (Fernandez-Rio \& Menendez-Santurio, 2017), and a hybrid of TGfU and Sport education (Gil-Arias et al., 2017). Five studies adopted the TARGET framework to design a task-oriented/ mastery motivational climate in an intervention program (Abós et al., 2017; Barkoukis et al., 2008; Bortoli et al., 2015; Gray et al., 2009; İlker \& Demirhan, 2013). Two studies investigated the effects of a school-based multicomponent intervention including curricular strategies, school environment, and parental support (Neumark-Sztainer et al., 2010; Pardo et al., 2016). The intervention called New Moves designed by Neumark-Sztainer et al. (2010) provided the teacher guidelines for giving choice, shaping a safe and fun environment, and providing positive feedback. Pardo et al.'s (2016) intervention called Sigue la Huella included a self-determination theory (SDT; Ryan \& Deci, 2017) based teacher training to foster student autonomy, perceived competence, and feelings of relatedness. The remaining five studies designed intervention programs based on specific concepts and frameworks such as student-activated teaching (Chatzipanteli et al., 2015), stress coping (Lang et al., 2016, 2017), autonomy supportive teaching (Leptokaridou et al., 2016), and individualized teacher frame of reference (Schmidt et al., 2013).

Methodology. There were 20 quantitative studies and four qualitative studies. Two studies used a mixed-methods design. Selfreport questionnaires were used to measure affective outcomes in quantitative studies. Qualitative methods included semistructured interviews, focus group interviews, and researchers' field notes.

Learning outcomes. It is important to elaborate which themes of affective outcomes emerged in the review as this allows us to discuss how teaching and lesson context align with each theme. The following themes were identified through thematic analysis in a theory-driven approach: motivation, emotional responses, selfconcept, and resilience. With respect to the first theme, motivation is defined here from the perspective of SDT (Ryan \& Deci, 2017). Rather than considering motivation as a unitary concept, SDT describes motivation as a continuum emphasizing different types of behavioral regulation. Autonomous motivation refers to regulation of behavior involving experiences of volition and self-expression and is considered the optimal form of motivation, whereas controlled motivation denotes behavioral engagement characterized by feelings of internal or external pressure or coercion. Another type of motivation is amotivation defined as a lack of intentionality or motivation (Ryan \& Deci, 2017). According to SDT, motivation is also facilitated by three basic psychological needs: autonomy (i.e., feeling volition and willingness), competence (i.e., feeling effective and capable), and relatedness (i.e., feeling connected and involved; Ryan \& Deci, 2017). These psychological needs are to be 


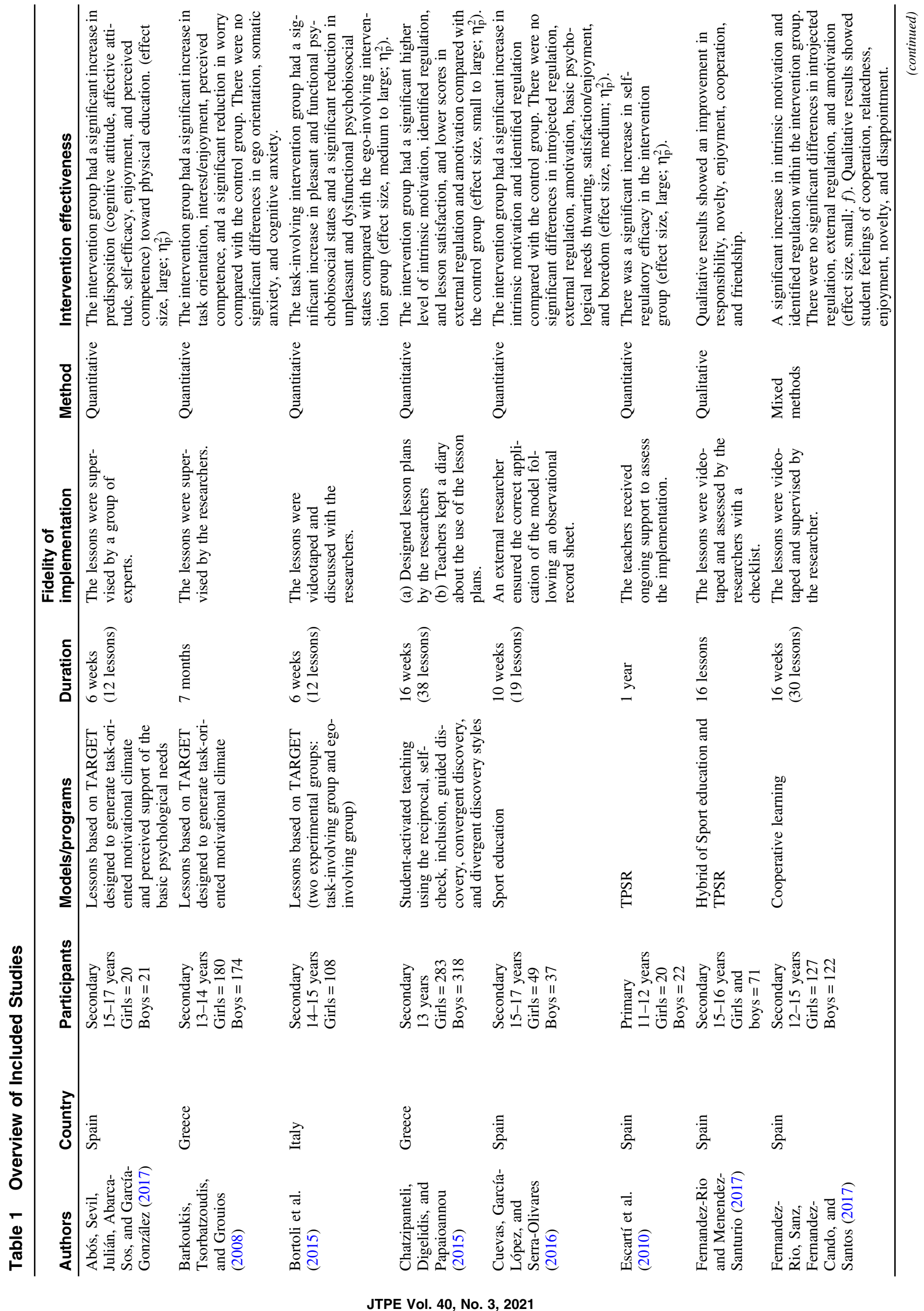




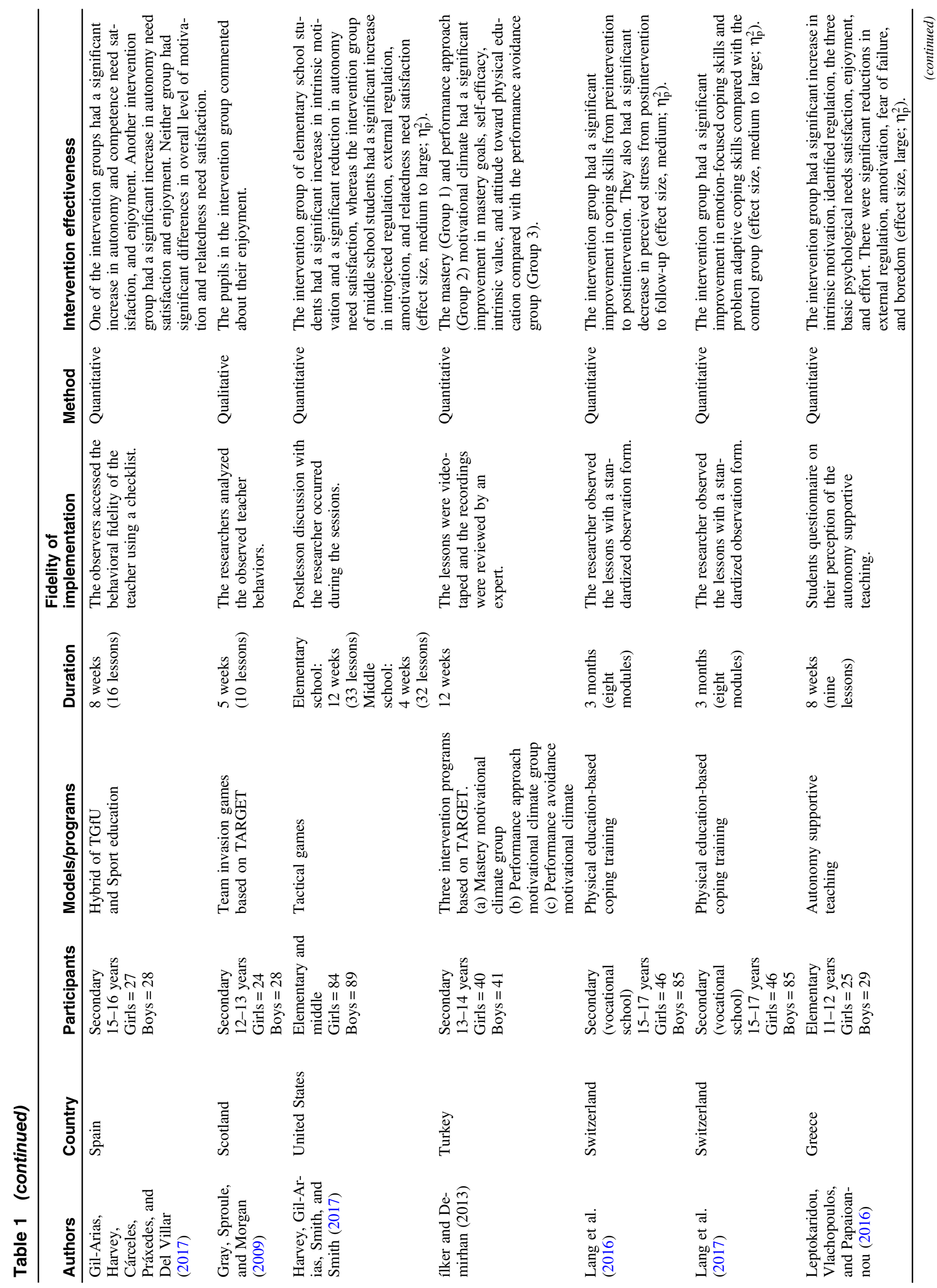




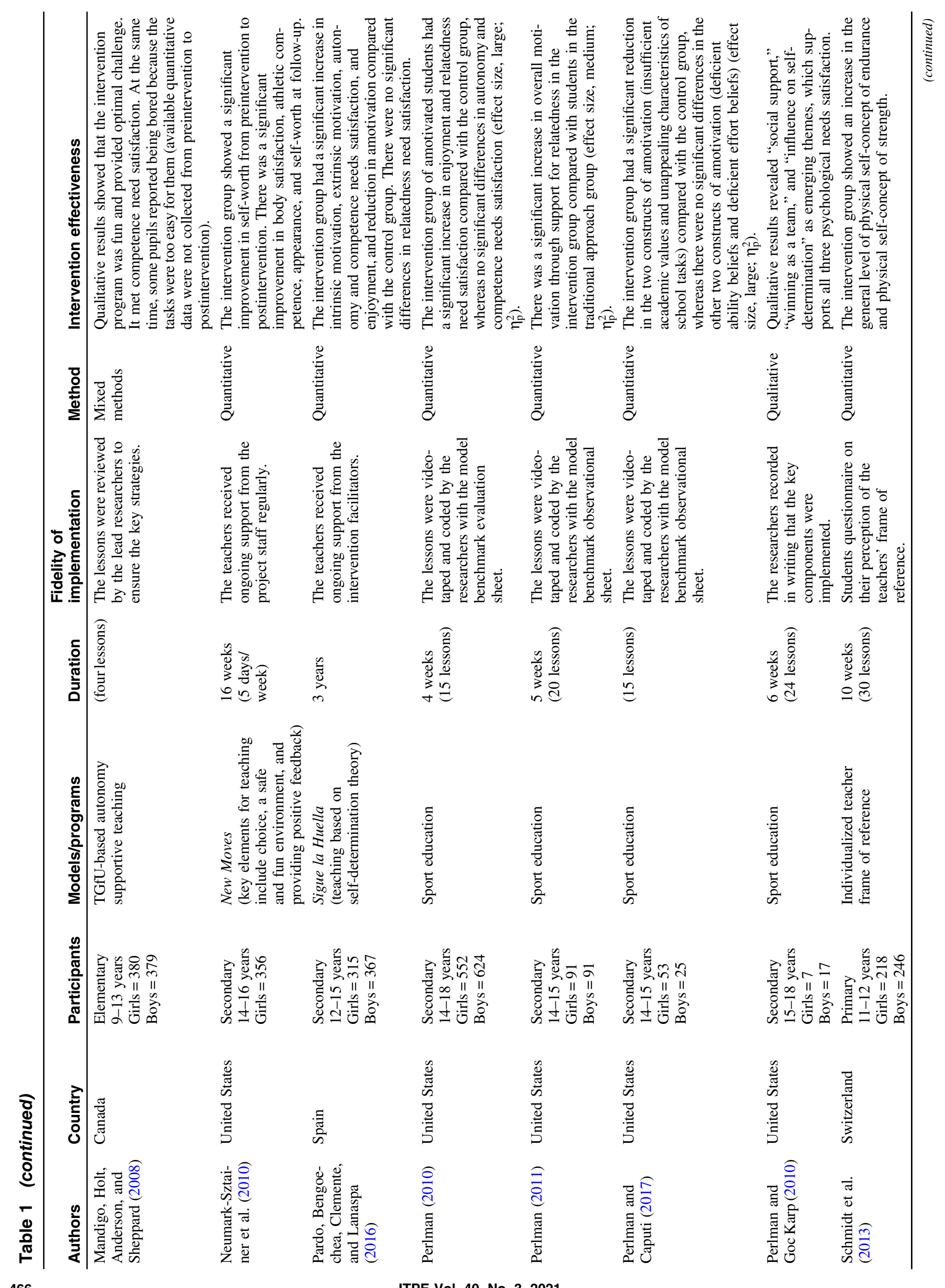




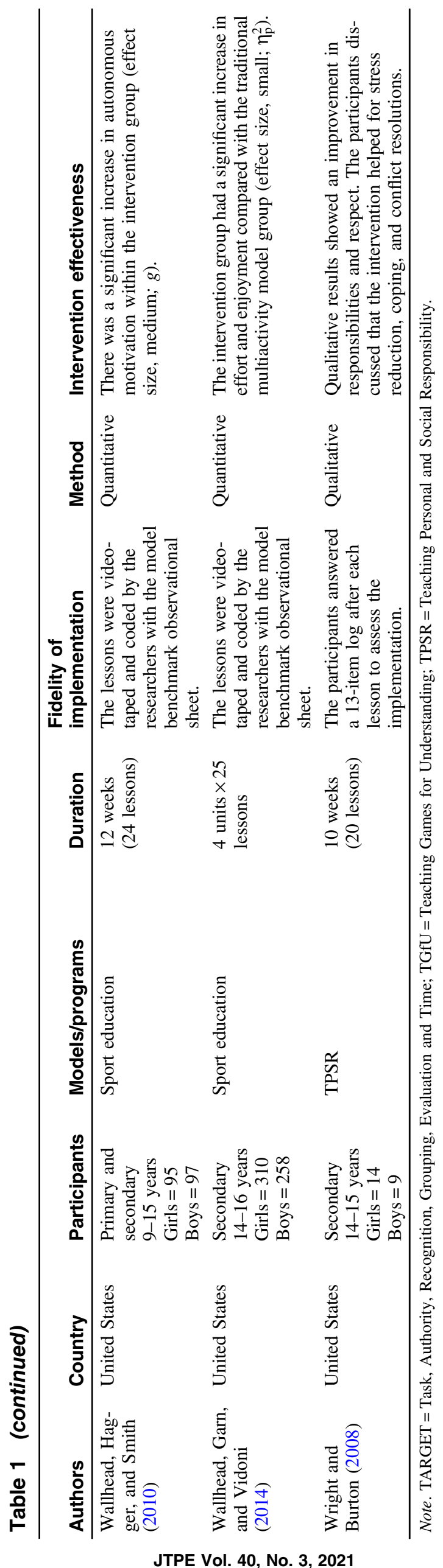


supported to achieve optimal levels of motivation. In regard to the second theme, affective outcomes including enjoyment, interest, satisfaction, effort, boredom, pleasure, fear, and worry were categorized as emotional responses. With regard to the third theme, self-concept refers to an individual's descriptive and evaluative perceptions of oneself (Estevan \& Barnett, 2018; Marsh \& Shavelson, 1985); in this review, both subcomponents of selfconcept (e.g., perceived competence, body satisfaction) and related constructs (e.g., self-efficacy, self-worth) are included under this theme. Finally, as to the fourth theme, an ability to recover from stress or misfortune is referred to as resilience (Masten, 2001).

\section{Intervention Effectiveness}

With regard to data analysis, quantitative studies compared differences in affective outcomes as measured by self-report surveys between the intervention group and control group (i.e., intercomparison) and/or changes within the intervention group (i.e., intracomparison). Most studies reported effect sizes, which can be interpreted as small $\left(\eta_{\mathrm{p}}^{2}=.01, \eta_{\mathrm{p}}^{2}=.01, f=0.10, g=0.20\right)$, medium $\left(\eta_{\mathrm{p}}^{2}=.06, \eta_{\mathrm{p}}^{2}=.06\right.$, $f=0.25, g=0.50)$, or large $\left(\eta_{\mathrm{p}}^{2}=.14, \eta_{\mathrm{p}}^{2}=.14, f=0.40, g=0.80\right.$; Fritz, Morris, \& Richler, 2012). Qualitative studies described participants' feelings and experiences following the intervention program.

Motivation. Four studies showed significant effects for autonomy need satisfaction through a hybrid of TGfU and Sport Education (Gil-Arias et al., 2017), Sport Education (Perlman \& Goc Karp, 2010), and autonomy supportive teaching (Leptokaridou et al., 2016; Pardo et al., 2016), whereas one study did not show significant effects for autonomy need satisfaction in Sport education (Perlman, 2010). With regard to competence need satisfaction, four studies reported significant effects for competence need satisfaction through lessons using autonomy supportive teaching (Leptokaridou et al., 2016; Pardo et al., 2016) and Sport education (Gil-Arias et al., 2017; Perlman \& Goc Karp, 2010). Moreover, two studies reported a positive change of perceived competence with a large effect size through lessons based on TARGET (Abós et al., 2017; Barkoukis et al., 2008). Nonetheless, similar to autonomy need satisfaction, one study adopting a Sport education program did not find significant differences for competence need satisfaction (Perlman, 2010). Three studies showed significant effects for relatedness need satisfaction with medium to large effect sizes through autonomy supportive teaching (Leptokaridou et al., 2016) and Sport Education (Perlman, 2010; Perlman \& Goc Karp, 2010). One qualitative study showed positive feelings of relatedness after participating in Cooperative Learning (Fernandez-Rio et al., 2017). However, two studies reported no significant differences in relatedness following a hybrid program of TGfU and Sport education (Gil-Arias et al., 2017) and autonomy supportive teaching (Pardo et al., 2016).

Most studies showed positive effects on motivation through a student-activated teaching approach (Chatzipanteli et al., 2015), Sport education (Cuevas et al., 2016; Perlman \& Caputi, 2017), Cooperative Learning (Fernandez-Rio et al., 2017), Tactical Games Model (Harvey et al., 2017), and autonomy supportive teaching (Leptokaridou et al., 2016; Pardo et al., 2016). Two studies reported a significant decrease in controlled motivation with large effect sizes (Chatzipanteli et al., 2015; Leptokaridou et al., 2016). Four studies were successful in decreasing the level of amotivation among students with medium to large effect sizes (Chatzipanteli et al., 2015; Leptokaridou et al., 2016; Pardo et al., 2016; Perlman \& Caputi, 2017).

Emotional responses. Seven studies showed a positive effect on enjoyment, interest, or satisfaction with small to large effect sizes through lessons based on TARGET (Abós et al., 2017; Barkoukis et al., 2008), a hybrid of TGfU and Sport education (Gil-Arias et al., 2017), autonomy supportive teaching (Leptokaridou et al., 2016; Pardo et al., 2016), and Sport education (Perlman, 2010; Wallhead et al., 2014). In addition, four qualitative studies showed responses of enjoyment after participating in a hybrid program of Sport education and TPSR (Fernandez-Rio \& Menendez-Santurio, 2017), Cooperative Learning (Fernandez-Rio et al., 2017), team invasion games based on TARGET (Gray et al., 2009), and TGfUbased autonomy supportive lessons (Mandigo et al., 2008). Two studies showed that there was a significant increase in effort with small to large effect sizes through autonomy supportive teaching (Leptokaridou et al., 2016) and Sport education (Wallhead et al., 2014). One study presented a significant large decrease in boredom and fear of failure through autonomy supportive teaching (Leptokaridou et al., 2016). Bortoli et al. (2015) reported a significant moderate increase in the level of pleasant/functional psychobiosocial states and a significant large decrease in the level of unpleasant/dysfunctional psychobiosocial states through lessons based on TARGET.

In some qualitative studies, negative experiences have also been reported. For example, a student who experienced Cooperative Learning (Fernandez-Rio et al., 2017) was disappointed: "when I had trouble with the difficult challenges, many classmates laugh at me, and that discouraged me more and more" (p. 100). In another study, a student who was in the TGfU-based autonomy supportive lessons (Mandigo et al., 2008) commented that, "I did not like the lesson because it was boring and it was like a grade 2 or 3 game, not fun for people my age" (p. 417).

Self-concept. Three studies reported a positive intervention effect on self-efficacy with a large effect size through lessons based on TARGET (Abós et al., 2017; İlker \& Demirhan, 2013) and TPSR (Escartí et al., 2010). Strategies used were self-referenced criteria and avoidance of social comparisons. Escartí et al. (2010) showed that a TPSR program facilitated students' self-regulatory efficacy (i.e., the ability to resist the negative pressure of peers, family, and community). Neumark-Sztainer et al. (2010) showed a significant positive effect of New Moves on perceived athletic competence, self-worth, and body satisfaction. This intervention program incorporates physical education lessons, individual counseling sessions, and support for parents. Schmidt et al. (2013) showed that an intervention based on the concept of individualized teacher frame of reference led to an increase in physical self-concept through lessons. The emphasis on the individual learning process when assessing performance influenced positive effects on physical self-concept.

Resilience. The studies on resilience demonstrated that the students significantly improved their adaptive coping skills through a school-based coping training program (Lang et al., 2016, 2017). Also, a significant decrease in stress was observed at follow-up (Lang et al., 2016). Wright and Burton (2008) reported that a TPSR program adopting a tai chi context had a positive effect on students' stress coping skills.

\section{Fidelity of Implementation}

Fidelity of implementation refers to the degree to which a program was delivered as intended. The authors of the studies used a number of methods to check and ensure fidelity of implementation. In most studies, researchers conducted video analysis, observations, or provided ongoing support during the interventions. For instance, 
in the study of Harvey et al. (2017), teachers had a regular postlesson discussion with the researchers. Questionnaires on students' perception of teaching were used in three studies as another method to assess fidelity (Leptokaridou et al., 2016; Schmidt et al., 2013; Wright \& Burton, 2008). A questionnaire was used in every lesson to ask students to what extent their teacher's behavior was based on the key elements of an intervention. Leptokaridou et al. (2016) and Schmidt et al. (2013) found significant differences in these scores between the intervention group and the control group. The study of Wright and Burton (2008) did not include a control group, but secured a satisfactory level of implementation fidelity. Finally, the study of Chatzipanteli et al. (2015) used lesson plans (designed by the researchers) and teacher diaries on lesson plan delivery to ensure fidelity of implementation.

\section{Discussion}

The aim of the present study was to review the evidence on affective learning in physical education interventions. The findings of the included studies showed that the interventions generally have a positive effect on students' affective outcomes such as motivation, emotional response, self-concept, and resilience. The findings of this review revealed different ways to enhance affective learning, although not all interventions were successful in improving each intended learning outcome.

\section{Affective Learning in Physical education}

Motivation. The findings show that basic psychological need satisfaction can be met when using autonomy-supportive teaching or pedagogical models. For instance, the lesson unit based on autonomy supportive teaching designed by Leptokaridou et al. (2016) and the Sport education program designed by Perlman and Goc Karp (2010) showed positive effects on autonomous motivation and all three basic needs satisfaction. However, there were studies that only showed significant changes for some affective outcomes. The hybrid program of TGfU and Sport education designed by Gil-Arias et al. (2017) did not have any significant influence on motivation and relatedness need satisfaction, although the intervention group showed a significant increase in autonomy and competence need satisfaction. Perlman (2011) found significant effects on relatedness need satisfaction and overall level of motivation following a Sport education program even though there were no significant effects on autonomy and competence need satisfaction. This suggests that autonomous motivation may be more strongly influenced by relatedness need satisfaction than by autonomy or competence need satisfaction. As noted by Chu and Zhang (2018), relatedness is a key factor of motivation in physical education and should be considered in teaching and lesson content.

A number of common teaching strategies and lesson content were found among the interventions to support motivation and need satisfaction. For instance, this review revealed that providing choice in tasks not only increases autonomous motivation and decreases controlled motivation and amotivation, but it also improves students' autonomy need satisfaction. The pedagogical importance of offering choice has been recognized in previous literature (Haerens, Aelterman, Vansteenkiste, Soenens, \& Van Petegem, 2015; Mitchell, Gray, \& Inchley, 2015). From the perspective of SDT, offering choice promotes students' feelings of autonomy (Ryan \& Deci, 2017). It is important to note that choices of lesson content in physical education should not be confused with free play (Oliver \& Kirk, 2015). Teachers should thus provide students with meaningful choices when engaging with learning activities (Aelterman et al., 2019). To this end, allowing students to choose from a variety of content and tasks (e.g., choices as to the size and type of equipment, choices of lesson content and choices in spending time on a task) can produce an increase in all three basic psychological needs satisfaction that lead to changes in autonomous motivation (Leptokaridou et al., 2016; Perlman \& Goc Karp, 2010). Nevertheless, while offering choice is generally considered positive, there was a study where this teaching strategy had little effect on amotivated students. Perlman (2010) discussed that the limited access of choice over behavior (e.g., taking a leadership role) might influence the lack of autonomy need satisfaction for amotivated students. Teachers should, therefore, consider the needs of their students and the class context when considering implementing choice.

Encouraging peer feedback and asking deductive questions were also found to be effective strategies to enhance autonomous motivation and basic psychological needs satisfaction. These pedagogical practices support students in taking responsibility for their own learning and were especially present in programs characterized by student-activated teaching (Chatzipanteli et al., 2015) and autonomy-supportive teaching (Leptokaridou et al., 2016; Pardo et al., 2016). This focus on the individual learning process is also present in the TARGET framework, which can enhance students' positive emotional responses and self-concept.

It is worthwhile to note that the intervention programs targeting motivation and need satisfaction had different ranges of duration, which might have influenced their effectiveness. For instance, studies with an 8-week program showed a positive influence on basic psychological needs satisfaction (Leptokaridou et al., 2016; Gil-Arias et al., 2017). Interventions successful in enhancing autonomous motivation lasted between 8 and 16 weeks (Chatzipanteli et al., 2015; Cuevas et al., 2016; Fernandez-Rio et al., 2017; Harvey et al., 2017; Leptokaridou et al., 2016; Pardo et al., 2016). In contrast, a 4-week program did not demonstrate any significant effects (Perlman, 2010). Although there are no clear guidelines regarding program duration, it is possible that a minimum length of 8 weeks may be needed to observe significant changes in students' basic psychological need satisfaction and autonomous motivation.

Emotional responses. Positive emotional responses by students such as enjoyment, interest, and satisfaction are one of the most prominent outcomes. Many interventions in this review had positive effects on enjoyment and interest due to their novelty. Participants might have felt that an intervention was a new experience and different to what they had experienced before in physical education. In fact, novelty is conceptualized as an important element of intrinsic motivation (Ryan \& Deci, 2000). More recently, González-Cutre et al. (2016) found that novelty is positively related to the three basic psychological needs and autonomous motivation. Novelty could be considered a potential factor in enhancing motivation and further emotional responses rather than just a tentative emotion. Even though there were many key elements to produce positive emotional responses, studentcentered teaching strategies were a common pedagogical feature and included providing opportunities for learners to plan their own learning tasks, listening to students' wishes and opinions, and enabling self-paced learning. Nonetheless, negative student experiences were reported in cases where peers were perceived as not being supportive in group work (e.g., laughing at other students' performance; Fernandez-Rio et al., 2017) or lesson activities were not challenging enough for more competent students (Mandigo 
et al., 2008). To this end, teachers might need to consider student behavior in group activities and provide individual additional support to ensure positive engagement and collaboration among students. Moreover, teachers can provide differentiated tasks to allow students to work at their individual level.

Self-concept. This review also revealed that intervention programs had positive effects on self-concept and related outcomes. For instance, the individualized teacher frame of reference was successful in enhancing self-concept (Schmidt et al., 2013). Teaching based on this framework emphasizes individual learning process (Lüdtke, Köller, Marsh, \& Trautwein, 2005), which is relevant to a task-oriented motivational climate. TARGET-based programs were also effective in improving perceived competence, as it can create an optimal motivational climate for individuals to master tasks. Implementing lessons that focus on personal improvement and differentiation would thus have a positive effect of self-concept. The importance of self-concept is also raised by Kerner, Haerens, and Kirk (2018) who argued that strategies to promote positive feelings of body image and competence among students should be considered in physical education contexts because a number of students might experience body image disturbance due to social dynamics within physical education. Furthermore, it may be necessary to consider the wider school environment; for instance, Neumark-Sztainer et al. (2010) delivered a multicomponent intervention incorporating social support through individual counseling sessions and parent outreach to improve body satisfaction and self-worth.

Resilience. With regard to resilience, Lang et al. (2016, 2017) proposed that physical education can contribute to the successful acquisition of new knowledge and skills to cope with stress. Their intervention program focused on promoting adaptive coping skills in students. The teachers intended to introduce challenging tasks and create stressful situations in physical education contexts. The modules aimed at improving problem-solving and practicing relaxation techniques (e.g., positive self-talk) after the students reflected on the sources of stress and negative thoughts in physical education contexts. While the interventions of Lang et al. (2016, 2017) were planned and designed for stress coping skills, Wright and Burton (2008) used the TPSR model to teach responsibility behavior. Interestingly, they noted that stress reduction occurred because the tai chi context and associated activities blended effectively with TPSR. These outcomes highlight the value of incorporating mental health as a main target in pedagogies of affect.

\section{Fidelity of Implementation}

A range of fidelity of implementation methods have been used, including video analysis, observation, ongoing support, teacher diary/log, and student questionnaires. This review included studies that provided measures of fidelity of implementation, although there may be disagreement on the choice of method. Some might argue that a student questionnaire is sufficient to assess the extent to which the teacher implemented an intervention program as intended, whereas others might not consider this to be an appropriate source of information to evaluate fidelity of implementation. Ideally, pedagogical research needs to consider the fidelity of implementation following Hastie and Casey's (2014) guidelines, which require a rich description of what the authors did exactly in terms of intervention planning and delivery. While their guidelines were developed for pedagogical models, they could be applied to other types of programs. It is important for readers to understand how the intervention programs work to ensure an effective adoption in future research and practice.

\section{Strengths, Limitations, and Future Research}

Major strengths of the present study include the use of different databases, quality assessment, and the alignment with the PRISMA statement. In addition, contrary to previous literature reviews (e.g., Harvey \& Jarrett, 2014; Hastie et al., 2011), fidelity of implementation was included as a selection criterion in the review process. As the included studies reported on fidelity of implementation, the findings in this review offer insights into pedagogical practices of physical education programs that focus on supporting affective learning. Nonetheless, there are some limitations that need to be mentioned. First, the included studies used predominantly quantitative measures. There is, perhaps, a need to include more qualitative evidence with a repeated data design to examine changes in participants' responses and experiences over time. Second, different assessment tools were used to measure specific outcomes, which makes it difficult to compare findings across studies. Other factors that limit comparisons between individual studies are the differences in program content and duration. Third, only a few studies included a follow-up measurement to evaluate long-term effects on affective outcomes. Documenting long-term effects of these intervention programs will help inform policy and practice. Fourth, only a few pedagogical interventions have been conducted in primary schools. More studies conducted in primary schools would be helpful to further develop pedagogies for affective learning within and across primary and secondary schools. Fifth, the available data reported in this systematic review are based on self-report measures. Data from lesson observations are needed to better explore and develop effective pedagogies of affect. This point is in line with previous studies, which highlight the importance of observing teaching behavior to better understand the relationship between teaching and student learning (Chu \& Zhang, 2018; Van den Berghe et al., 2014). There is a need to gain further direct evidence on teachers' actual behavior in supporting affective learning.

\section{Conclusions}

This systematic review presented an overview of empirical evidence on affective learning in physical education programs during the last decade. Affective outcomes were grouped into four themes: motivation, emotional responses, self-concept, and resilience. There were a number of programs and strategies that were successful in achieving affective learning. In particular, the use of pedagogical models and the TARGET framework was predominant in this review. Also, we identified that offering choice, encouraging peer feedback, asking deductive questions, focusing on personal improvement, and differentiation are effective teaching strategies that were widely used for affective learning. As current evidence on affective learning in physical education is largely based on self-report measures, future investigations should involve observational tools to further develop pedagogies of affect and inform teacher education programs on learning in the affective domain of health.

\section{References}

Abós, Á., Sevil, J., Julián, J.A., Abarca-Sos, A., \& García-González, L. (2017). Improving students' predisposition towards physical education 
by optimizing their motivational processes in an acrosport unit. European Physical Education Review, 23(4), 444-460. doi:10.1177/ 1356336 X16654390

Aelterman, N., Vansteenkiste, M., Haerens, L., Soenens, B., Fontaine, J.R., \& Reeve, J. (2019). Toward an integrative and fine-grained insight in motivating and demotivating teaching styles: The merits of a circumplex approach. Journal of Educational Psychology, 111(3), 497-521. doi:10.1037/edu0000293

Bailey, R., Armour, K., Kirk, D., Jess, M., Pickup, I., \& Sandford, R. BERA Physical Education and Sport Pedagogy Special Interest Group. (2009). The educational benefits claimed for physical education and school sport: An academic review. Research Papers in Education, 24(1), 1-27.

Barkoukis, V., Tsorbatzoudis, H., \& Grouios, G. (2008). Manipulation of motivational climate in physical education: Effects of a seven-month intervention. European Physical Education Review, 14(3), 367-387. doi:10.1177/1356336X08095671

Bortoli, L., Bertollo, M., Vitali, F., Filho, E., \& Robazza, C. (2015). The effects of motivational climate interventions on psychobiosocial states in high school physical education. Research Quarterly for Exercise and Sport, 86(2), 196-204. doi:10.1080/02701367.2014. 999189

Bunker, D., \& Thorpe, R. (1982). A model for the teaching of games in secondary schools. Bulletin of Physical Education, 18(1), 5-8.

Burns, R.D., Fu, Y., \& Podlog, L.W. (2017). School-based physical activity interventions and physical activity enjoyment: A meta-analysis. Preventive Medicine, 103, 84-90. doi:10.1016/j.ypmed.2017.08.011

Cale, L., \& Harris, J. (2013). "Every child (of every size) matters" in physical education! Physical education's role in childhood obesity. Sport, Education and Society, 18(4), 433-452. doi:10.1080/13573322. 2011.601734

Chatzipanteli, A., Digelidis, N., \& Papaioannou, A.G. (2015). Selfregulation, motivation and teaching styles in physical education classes: An intervention study. Journal of Teaching in Physical Education, 34(2), 333-344. doi:10.1123/jtpe.2013-0024

Chu, T.L., \& Zhang, T. (2018). Motivational processes in Sport Education programs among high school students: A systematic review. European Physical Education Review, 24(3), 372-394. doi:10.1177/ 1356336X17751231

Corbin, C.B. (2012). CH McCloy Lecture: Fifty years of advancements in fitness and activity research. Research Quarterly for Exercise and Sport, 83(1), 1-11. doi:10.1080/02701367.2012.10599819

Cuevas, R., García-López, L.M., \& Serra-Olivares, J. (2016). Sport Education model and self-determination theory: An intervention in secondary school children. Kinesiology: International Journal of Fundamental and Applied Kinesiology, 48(1), 30-38.

Demetriou, Y., \& Höner, O. (2012). Physical activity interventions in the school setting: A systematic review. Psychology of Sport and Exercise, 13(2), 186-196. doi:10.1016/j.psychsport.2011.11.006

Dusenbury, L., Brannigan, R., Falco, M., \& Hansen, W.B. (2003). A review of research on fidelity of implementation: Implications for drug abuse prevention in school settings. Health Education Research, 18(2), 237-256. doi:10.1093/her/18.2.237

Epstein, J. (1989). Family structure and students motivation: A development perspective. In C. Ames \& R. Ames (Eds.), Research on motivation in education (Vol. 3, pp. 259-295). New York, NY: Academic Press.

Escartí, A., Gutiérrez, M., Pascual, C., \& Llopis, R. (2010). Implementation of the personal and social responsibility model to improve selfefficacy during physical education classes for primary school children. International Journal of Psychology and Psychological Therapy, 10(3), 387-402.
Escartí, A., Llopis-Goig, R., \& Wright, P.M. (2018). Assessing the implementation fidelity of a school-based teaching personal and social responsibility program in physical education and other subject areas. Journal of Teaching in Physical Education, 37(1), 12-23. doi:10.1123/jtpe.2016-0200

Estevan, I., \& Barnett, L.M. (2018). Considerations related to the definition, measurement and analysis of perceived motor competence. Sports Medicine, 48(12), 2685-2694. doi:10.1007/s40279018-0940-2

Fernandez-Rio, J., \& Menendez-Santurio, J.I. (2017). Teachers and students' perceptions of a hybrid sport education and teaching for personal and social responsibility learning unit. Journal of Teaching in Physical Education, 36(2), 185-196. doi:10.1123/jtpe.2016-0077.

Fernandez-Rio, J., Sanz, N., Fernandez-Cando, J., \& Santos, L. (2017). Impact of a sustained Cooperative Learning intervention on student motivation. Physical Education and Sport Pedagogy, 22(1), 89-105. doi:10.1080/17408989.2015.1123238

Fritz, C.O., Morris, P.E., \& Richler, J.J. (2012). Effect size estimates: Current use, calculations, and interpretation. Journal of Experimental Psychology: General, 141(1), 2-18. doi:10.1037/a0024338

Gil-Arias, A., Harvey, S., Cárceles, A., Práxedes, A., \& Del Villar, F. (2017). Impact of a hybrid TGfU-Sport Education unit on student motivation in physical education. PLoS One, 12(6), e0179876. doi:10. 1371/journal.pone.0179876

González-Cutre, D., Sicilia, Á., Sierra, A.C., Ferriz, R., \& Hagger, M.S. (2016). Understanding the need for novelty from the perspective of self-determination theory. Personality and Individual Differences, 102, 159-169. doi:10.1016/j.paid.2016.06.036

Gray, S., Sproule, J., \& Morgan, K. (2009). Teaching team invasion games and motivational climate. European Physical Education Review, 15(1), 65-89. doi:10.1177/1356336X09105212.

Haerens, L., Aelterman, N., Vansteenkiste, M., Soenens, B., \& Van Petegem, S. (2015). Do perceived autonomy-supportive and controlling teaching relate to physical education students' motivational experiences through unique pathways? Distinguishing between the bright and dark side of motivation. Psychology of Sport and Exercise, 16(3), 26-36. doi:10.1016/j.psychsport.2014.08.013.

Harris, J.D., Quatman, C.E., Manring, M.M., Siston, R.A., \& Flanigan, D.C. (2014). How to write a systematic review. The American Journal of Sports Medicine, 42(11), 2761-2768. doi:10.1177/ 0363546513497567.

Harvey, S., Gil-Arias, A., Smith, M.L., \& Smith, L.R. (2017). Middle and elementary school students' changes in self-determined motivation in a basketball unit taught using the tactical games model. Journal of Human Kinetics, 59(1), 39-53. doi:10.1515/hukin-2017-0146

Harvey, S., \& Jarrett, K. (2014). A review of the game-centred approaches to teaching and coaching literature since 2006. Physical Education and Sport Pedagogy, 19(3), 278-300. doi:10.1080/17408989.2012. 754005

Harwood, C.G., Keegan, R.J., Smith, J.M., \& Raine, A.S. (2015). A systematic review of the intrapersonal correlates of motivational climate perceptions in sport and physical activity. Psychology of Sport and Exercise, 18, 9-25. doi:10.1016/j.psychsport.2014.11.005

Hastie, P.A., \& Casey, A. (2014). Fidelity in models-based practice research in sport pedagogy: A guide for future investigations. Journal of Teaching in Physical Education, 33(3), 422-431. doi:10.1123/jtpe. 2013-0141.

Hastie, P.A., de Ojeda, D.M., \& Luquin, A.C. (2011). A review of research on Sport Education: 2004 to the present. Physical Education and Sport Pedagogy, 16(2), 103-132. doi:10.1080/17408989.2010.535202

Hellison, D. (1995). Teaching responsibility through physical activity. Champaign, IL: Human Kinetics. 
Hellison, D., \& Wright, P.M. (2003). Retention in an urban extended day program: A process-based assessment. Journal of Teaching in Physical Education, 22(4), 369-381. doi:10.1123/jtpe.22.4.369

İlker, G.E., \& Demirhan, G. (2013). The effects of different motivational climates on students' achievement goals, motivational strategies and attitudes toward physical education. Educational Psychology, 33(1), 59-74. doi:10.1080/01443410.2012.707613

Inchley, J., Currie, D., Young, T., Samdal, O., Torsheim, T., Auguston, L., Mathison, F. . . Barnekow, V. (2016). Growing up unequal: Gender and socioeconomic differences in young people's and well-being. Health Behaviour in School-aged Children (HBSC) Study: International Report from the 2013/2014 Survey. WHO Regional Office for Europe. Retrieved from http://www.euro.who.int/en/publications/ abstracts/growing-up-unequal.-hbsc-2016-study-20132014-survey

Kerner, C., Haerens, L., \& Kirk, D. (2018). Understanding body image in physical education: Current knowledge and future directions. European Physical Education Review, 24(2), 255-265. doi:10.1177/ 1356336X17692508

Kirk, D. (2020). Precarity, critical pedagogy and physical education. London, UK: Routledge.

Lang, C., Feldmeth, A.K., Brand, S., Holsboer-Trachsler, E., Pühse, U., \& Gerber, M. (2016). Stress management in physical education class: An experiential approach to improve coping skills and reduce stress perceptions in adolescents. Journal of Teaching in Physical Education, 35(2), 149-158. doi:10.1123/jtpe.2015-0079.

Lang, C., Feldmeth, A.K., Brand, S., Holsboer-Trachsler, E., Pühse, U., \& Gerber, M. (2017). Effects of a physical education-based coping training on adolescents' coping skills, stress perceptions and quality of sleep. Physical Education and Sport Pedagogy, 22(3), 213-230. doi:10.1080/17408989.2016.1176130

Leptokaridou, E.T., Vlachopoulos, S.P., \& Papaioannou, A.G. (2016). Experimental longitudinal test of the influence of autonomy-supportive teaching on motivation for participation in elementary school physical education. Educational Psychology, 36(7), 1138-1159. doi:10.1080/01443410.2014.950195

Lüdtke, O., Köller, O., Marsh, H.W., \& Trautwein, U. (2005). Teacher frame of reference and the big-fish-little-pond effect. Contemporary Educational Psychology, 30(3), 263-285. doi:10.1016/j.cedpsych. 2004.10.002

Mandigo, J., Holt, N., Anderson, A., \& Sheppard, J. (2008). Children's motivational experiences following autonomy-supportive games lessons. European Physical Education Review, 14(3), 407-425. doi:10. 1177/1356336X08095673

Marsh, H.W., \& Shavelson, R. (1985). Self-concept: Its multifaceted, hierarchical structure. Educational Psychologist, 20(3), 107-123. doi:10.1207/s15326985ep2003_1

Masten, A.S. (2001). Ordinary magic: Resilience processes in development. American Psychologist, 56(3), 227-238. doi:10.1037/0003-066X.56.3.227.

Mitchell, F., Gray, S., \& Inchley, J. (2015). "This choice thing really works ..." Changes in experiences and engagement of adolescent girls in physical education classes, during a school-based physical activity programme. Physical Education and Sport Pedagogy, 20(6), 593-611. doi:10.1080/17408989.2013.837433

Mitchell, S., Oslin, J., \& Griffin, L. (2006). Teaching sport concepts and skills: A tactical games approach (2nd ed.). Champaign, IL: Human Kinetics.

Moher, D., Liberati, A., Tetzlaff, J., \& Altman, D.G. (2009). Preferred reporting items for systematic reviews and meta-analyses: The PRISMA statement. PLoS Medicine, 6(7), e1000097. doi:10.1371/ journal.pmed.1000097

Moher, D., Schulz, K.F., \& Altman, D.G.(2001). The CONSORT statement: Revised recommendations for improving the quality of reports of parallel-group randomised trials. The Lancet, 357(9263), 11911194. doi:10.1016/S0140-6736(00)04337-3

Moksnes, U.K., \& Reidunsdatter, R.J. (2019). Self-esteem and mental health in adolescents-level and stability during a school year. Norsk Epidemiologi, 28(1-2), 59-67. doi:10.5324/nje.v28i1-2.3052

Neumark-Sztainer, D.R., Friend, S.E., Flattum, C.F., Hannan, P.J., Story, M.T., Bauer, K.W., Feldman, S.B., \& Petrich, C.A. (2010). New moves-Preventing weight-related problems in adolescent girls: A group-randomized study. American Journal of Preventive Medicine, 39(5), 421-432. doi:10.1016/j.amepre.2010.07.017

Oliver, K.L., Hamzeh, M., \& McCaughtry, N. (2009). "Girly girls can play games/las niñas pueden jugar tambien”: Co-creating a curriculum of possibilities with 5th grade girls. Journal of Teaching in Physical Education, 28(1), 90-110. doi:10.1123/jtpe.28.1.90

Oliver, K.L., \& Kirk, D. (2015). Girls, gender and physical education: An activist approach. London, UK: Routledge.

Pardo, B.M., Bengoechea, E.G., Clemente, J.A.J., \& Lanaspa, E.G. (2016). Motivational outcomes and predictors of moderate-to-vigorous physical activity and sedentary time for adolescents in the sigue la huella intervention. International Journal of Behavioral Medicine, 23(2), 135-142. doi:10.1007/s12529-015-9528-5

Patel, V., Flisher, A.J., Hetrick, S., \& McGorry, P. (2007). Mental health of young people: A global public-health challenge. The Lancet, 369(9569), 1302-1313. doi:10.1016/S0140-6736(07)60368-7

Perlman, D.J. (2010). Change in affect and needs satisfaction for amotivated students within the Sport Education model. Journal of Teaching in Physical Education, 29(4), 433-445. doi:10.1123/jtpe.29.4.433

Perlman, D.J. (2011). Examination of self-determination within the Sport Education model. Asia-Pacific Journal of Health, Sport and Physical Education, 2(1), 79-92. doi:10.1080/18377122.2011.9730345

Perlman, D.J., \& Caputi, P. (2017). Examining the influence of Sport Education on the precursors of amotivation. European Physical Education Review, 23(2), 212-222. doi:10.1177/1356336X16643921

Perlman, D.J., \& Goc Karp, G. (2010). A self-determined perspective of the sport education model. Physical Education and Sport Pedagogy, 15(4), 401-418. doi:10.1080/17408980903535800

Pozo, P., Grao-Cruces, A., \& Pérez-Ordás, R. (2018). Teaching personal and social responsibility model-based programmes in physical education: A systematic review. European Physical Education Review, 24(1), 56-75. doi:10.1177/1356336X16664749

Ryan, R.M., \& Deci, E.L. (2000). Self-determination theory and the facilitation of intrinsic motivation, social development, and well-being. American Psychologist, 55(1), 68-78. doi:10.1037/0003-066X.55.1.68

Ryan, R.M., \& Deci, L.E. (2017). Self-determination theory: Basic psychological needs in motivation, development, and wellness. New York, NY: Guildford Press.

Schmidt, M., Valkanover, S., Roebers, C., \& Conzelmann, A. (2013). Promoting a functional physical self-concept in physical education: Evaluation of a 10-week intervention. European Physical Education Review, 19(2), 232-255. doi:10.1177/1356336X13486057

Siedentop, D. (1994). Sport education: Quality PE through positive sport experiences. Champaign, IL: Human Kinetics.

Van den Berghe, L., Vansteenkiste, M., Cardon, G., Kirk, D., \& Haerens, L. (2014). Research on self-determination in physical education: Key findings and proposals for future research. Physical Education and Sport Pedagogy, 19(1), 97-121. doi:10.1080/17408989.2012. 732563

Vandenbroucke, J.P., von Elm, E., Altman, D.G., Gøtzsche, P.C., Mulrow, C.D., Pocock, S.J., ... Eggar, M. (2007). Strengthening the reporting of observational studies in epidemiology (STROBE): Explanation and elaboration. PLoS Medicine, 4(10), e297. doi:10.1371/journal. pmed.0040297 
Wallhead, T.L., Garn, A.C., \& Vidoni, C. (2014). Effect of a Sport Education program on motivation for physical education and leisure-time physical activity. Research Quarterly for Exercise and Sport, 85(4), 478-487. doi:10.1080/02701367.2014.961051

Wallhead, T.L., Hagger, M., \& Smith, D.T. (2010). Sport Education and extracurricular sport participation: An examination using the trans-contextual model of motivation. Research Quarterly for Exercise and Sport, 81(4), 442-455.

Wright, P.M., \& Burton, S. (2008). Implementation and outcomes of a responsibility-based physical activity program integrated into an intact high school physical education class. Journal of Teaching in Physical Education, 27(2), 138-154. doi:10.1123/jtpe.27.2.138 